\title{
Versatility of male curlews Numenius arquata preying upon Nereis diversicolor: deploying contrasting capture modes dependent on prey availability
}

\author{
Leo Zwarts ${ }^{1}$, Peter Esselink ${ }^{2}$ \\ ${ }^{1}$ Rijkswaterstaat Flevoland, PO Box 600, 8200 AP Lelystad, The Netherlands \\ ${ }^{2}$ Zoological Laboratory, University of Groningen, PO Box 14,9750 AA Haren, The Netherlands
}

\begin{abstract}
Curlews Numenius arquata use 2 methods to capture ragworms Nereis diversicolor: they search for worms at the surface, which are taken with a single peck (called $N_{\text {peck }}$ ) and/or they search for visual cues, such as burrow entrances, and probe deep to extract the worm from the burrow (called $\mathrm{N}_{\text {probel }}$. It is argued that male curlews select predominantly active worms, which are either grazing at the surface $\left(\mathrm{N}_{\text {peck }}\right)$ or are filter feeding within their burrows $\left(\mathrm{N}_{\text {probe }}\right.$ and sometimes $\mathrm{N}_{\text {peck }}$ ). Profitability ( $\mathrm{mg} \mathrm{s}^{-1}$ handling) increases with worm length and is greater for $N_{\text {peck }}$, because of its shorter handling time, than for $N_{\text {probe }}$. Worms of both prey types $\leq \mathrm{ca} 6 \mathrm{~cm}$ are ignored, since profitability is below the intake rate ( $\mathrm{mg} \mathrm{s}^{-1}$ feeding). During low water there is a shift from $\mathrm{N}_{\text {probe }}$ to $\mathrm{N}_{\text {peck, }}$ which can be explained by changes in feeding behaviour of the worms. $N_{\text {probe }}$ common in summer, disappears during autumn due to the increase of burrow depth (with the corresponding decrease of worms accessible as $\mathrm{N}_{\text {probe }}$ ), and to a reduction in filter feeding of the worm, which means that fewer traces are visible. Curlew search rate increases if, relatively, many prey are of the $\mathrm{N}_{\text {peck }}$ type. There appears to be a tradeoff between search rate and probability of detection of conspicuous $N_{\text {peck }}$ and cryptic $N_{\text {probe }}$. No evidence was found that curlews ignore one prey type and selectively search for the other we conclude that (1) unprofitable prey sizes are ignored, (2) the greater part of the profitable prey are not available. being hidden in the substrate and mostly not accessible even when detectable, (3) curlews continuously readjust their capture technique to changes in the available food supply.
\end{abstract}

\section{INTRODUCTION}

The density of available prey is a major factor determining the feeding behaviour of a predator, but because prey availability cannot usually be measured adequately, absolute prey density is usually measured instead. The implicit assumption is that the proportion of available prey does not differ spatially or temporally. This study shows that there is a very large variation in the fraction of a burrow-dwelling prey species, ragworm Nereis diversicolor, which is actually available to a wading bird, curlew Numenius arquata. The feeding behaviour of the bird can even be described as a continuous adjustment to changes in the available food supply (Wanink \& Zwarts 1985).

Ragworm is a major prey for estuarine wader species throughout its range on the intertidal mudflats along the coast of Europe and NW Africa. Analyses of faeces, pellets and gizzards of waders in different areas and also direct observations on prey selection shows that this species is one of the main prey of about 15 wader species and the dominant prey of at least 5 waders: avocet Recurvirostra avosetta, grey plover Pluvialis squatarola, curlew sandpiper Calidris ferruginea, bartailed godwit Limosa lapponica (particularly $q q$ ) and curlew (particularly ơ) (Höfmann \& Hoerschelmann 1969, Zwarts 1974, Goss-Custard et al. 1977. Evans et al. 1979, Ens \& Zwarts 1980a, Townshend 1981, Kersten \& Piersma 1984, Worrall 1984).

The species is an important prey for birds because it is common, profitable and detectable as well as accessible. It is a common species with a wide distribution over estuarine flats where it can occur in high densities: 500 to 500000 juveniles $\mathrm{m}^{-2}$ in summer and 50 to 200 adults $\mathrm{m}^{-2}$ (1+ year) (Linke 1939, Dales 1950 , Smidt 1951, Muus 1967, Wolff 1973, Chambers \& Milne 
1975, Beukema 1976, Essink 1978, Dankers \& Beukema 1981). It is a profitable prey for waders and the black-headed gull Larus ridibundus (Goss-Custard 1977. Curtis et al. 1985, this study) since it can be handled rapidly, whereas the flesh weight is high compared with most other common estuarine worm species (Beukema 1976). It is also a detectable and accessible prey, especially easy to capture during grazing excursions at the surface around its burrow. A worm which filters food from the overlying water spends half of its time near one of the entrances of its burrow (Harley 1953, Goerke 1966) and thus also within reach of most waders' bills. When disturbed at or near the surface, however, a ragworm retreats quickly to the bottom of its burrow (Vader 1964). A small fraction of worms then remain accessible for 3 long-billed waders: oystercatcher Haematopus ostralegus (bill length 6 to $8 \mathrm{~cm}$ ), bar-tailed godwit (bill 7 to $10 \mathrm{~cm}$ ) and curlew (bill 10 to $16 \mathrm{~cm}$ ). The curlew, however, is the only wader able to capture Nereis diversicolor in their burrows throughout the year (Esselink \& Zwarts 1989 [companion article]).

The fraction of worms accessible to a probing wader can be calculated if its bill length and the depths of the burrows are known (Fig. 12 in Esselink \& Zwarts 1989). However, if the same wader preys on surface-feeding worms, the frequency with which the worms emerge from their burrows provides a more relevant measure of prey accessibility (Fig. 9 in Esselink \& Zwarts 1989). The accessibility of Nereis diversicolor to waders is thus complex to quantify.

This paper deals with curlews feeding on Nereis diversicolor. There is a remarkable difference in the feeding of individual curlews, even when specializing on this prey. This variation is greatly reduced when birds with the same bill length are compared. All data presented here pertain to male curlews (bill 10 to 12.5 $\mathrm{cm}$ ); the problem of individual variation will be treated elsewhere.

We distinguish 2 methods of prey capture: (1) worms which are taken from the surface or the entrance of the burrow are classified as $N_{\text {peck, }}$ (2) worms taken from the depths of the burrow are referred as $N_{\text {probe }}$.

This paper focuses on 2 questions: Can size selection be explained by the profitability and availability (thus accessibility and detectability) of the different size classes of Nereis diversicolor? How does a curlew cope with variations in prey accessibility within a tidal cycle and during the course of the year?

\section{METHODS}

Study area. The study was carried out on intertidal flats along the Frisian coast, Dutch Wadden Sea $\left(53^{\circ} 25^{\prime} \mathrm{N}, 6^{\circ} 04^{\prime} \mathrm{E}\right)$ from 1979 to 1982 inclusive. Most data were collected in late summer. Four observation towers were erected, around which 274 plots of 0.1 ha and 85 plots of 0.06 ha were pegged out, and each year 400 to 800 small plots of $25 \mathrm{~mm}^{-2}$ were staked out 10 to $200 \mathrm{~m}$ from one of the towers.

The larger part of the study area was situated between 10 and $30 \mathrm{~cm}$ below mean sea level, which corresponds to an emersion period of 37 to $43 \%$ per tidal cycle. The clay content $(<2 \mu \mathrm{m})$, determined for the upper $25 \mathrm{~cm}$ of the substrate, varied between 0.8 and $10.8 \%$, but at most sites it was 4 to $5 \%$, with a median grain size of $95 \mu \mathrm{m}$ (excluding the fraction $<16 \mu \mathrm{m}$ ) (Zwarts 1988). Water level in a nearby creek and mud temperature at a depth of 2 to $3 \mathrm{~cm}$ were measured continuously

Curlews. There were 3000 curlews present in the study area between July and April; 250 of these birds were marked individually with 2 colour rings. This paper is based upon work done on 24 colour-banded and 28 unbanded curlews which, because of their territorial behaviour and consequent extreme site fidelity, could be recognized individually (Ens \& Zwarts 1980b). About $10 \%$ of the observations concern birds which were not identified as individuals. Bill length of marked birds was known and was estimated for the unbanded ones. The estimation error - as determined for the marked birds - was small and usually $\leq 1 \mathrm{~cm}$, thus $<10 \%$ (Ens \& Zwarts 1980a and unpubl.).

Individual curlews were observed continuously, usually during the entire low water period, by 2 persons using a zoom-telescope (magnification 15 to $60 \times$ ) and a mirror-telescope $(40 \times)$ ). The following data were noted or registered on tape: (1) plot coordinates, (2) type of prey taken, (3) prey size (using bill length or size of colour ring as a reference), (4) duration of 4 types of activity to the nearest second: handling time (the curlew catches and swallows a prey; if handling is preceeded by probing this is always a part of the handling time); probing time (the curlew probes a greater part of its bill into the substrate without finding a prey); searching time (feeding time without probing

Table 1. Numenius arquata. Search rate predicted by the grid method' (explanation in the text) compared to the search rate as derived from the product of pace length (as measured from the prints in the mud) and pace frequency. All data were collected for one curlew observed an entire low water period

\begin{tabular}{|lcc|}
\hline Search rate & Mean \pm SE & $n$ \\
\hline Grid method $\left(\mathrm{cm} \mathrm{s}^{-1}\right)$ & $22.6 \pm 0.02$ & 180 \\
& & \\
Pace rate $\times$ pace length $\left(\mathrm{cm} \mathrm{s}^{-1}\right)$ & $22.3 \pm 25.2$ & \\
Pace rate (pace $\left.{ }^{-1}\right)$ & $1.8 \pm 0.02$ & 63 \\
Pace length $(\mathrm{cm})$ & $13.6 \pm 0.68$ & 20 \\
\hline
\end{tabular}




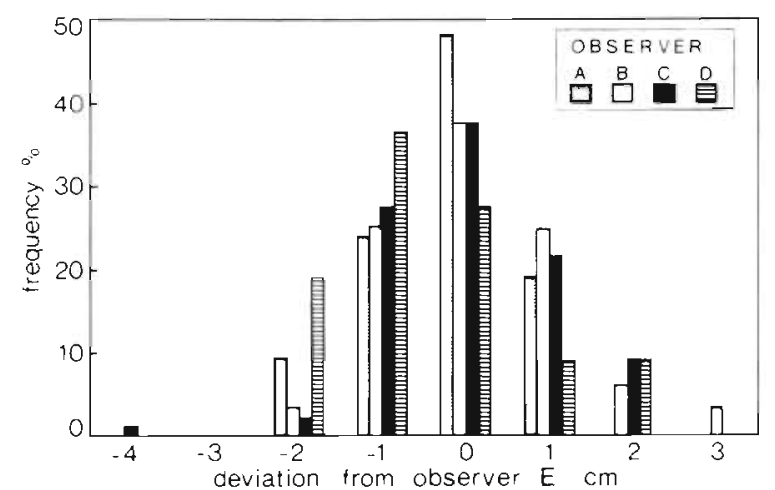

Fig. 1. Comparison between observers who estimated lengths of Nereis diversicolor taken by a curlew. Frequency distributions show agreement of 4 different observers (A: $\mathrm{n}=32 ; \mathrm{B}: \mathrm{n}$ $=32 ; \mathrm{C}: \mathrm{n}=56 ; \mathrm{D}: \mathrm{n}=11$ ) with Observer E. Most worms were 9 to $14 \mathrm{~cm}$

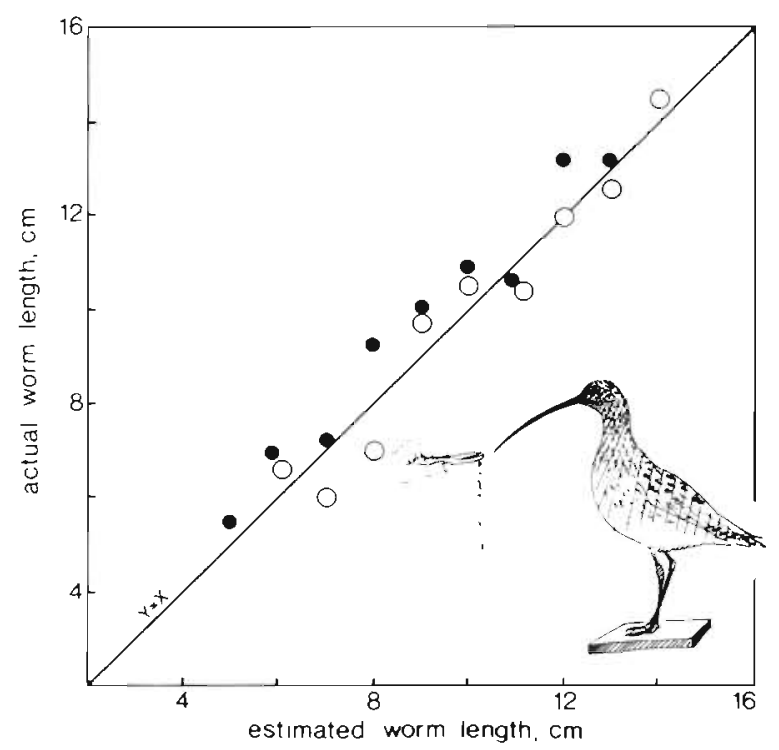

Fig. 2. Nereis diversicolor. Worm size measured in the laboratory (maximal length of creeping worms; see Esselink \& Zwarts 1989) as a function of estimated worm size, averaged for 5 observers using a telescope at a distance of $100 \mathrm{~m}$. Worms were held near the bill of 2 stuffed curlews (0: bill length $11.7 \mathrm{~cm}, \mathrm{n}=136 ; \bullet: 14.7 \mathrm{~cm}, \mathrm{n}=74$ )

and handling; single pecks [duration $<1$ s] are considered as part of the searching time); non-feeding time (preening, resting and aggression, but kleptoparasitism is considered as part of the feeding time).

Additional information was collected for curlews feeding within the grid of $5 \times 5 \mathrm{~m}$ plots around the hides, viz. the habitat from which the prey was taken (water film or dry surface) and coverage by water film (estimated from the tower as \% of the surface in the $5 \times 5 \mathrm{~m}$ plot visited).

All observations were pooled in 3 min periods. The analyses for this paper are confined to 3 min periods

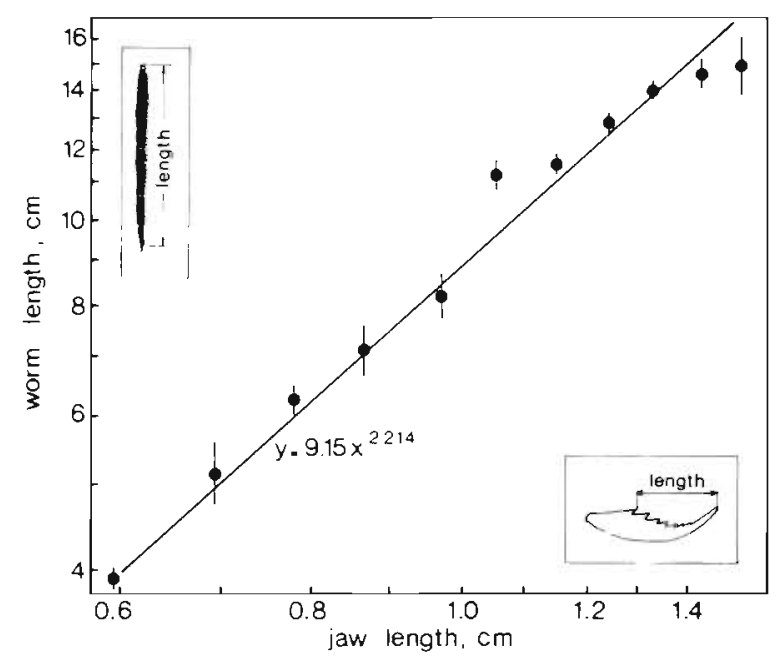

Fig. 3. Nereis diversicolor. Worm length ( $\mathrm{cm} \pm \mathrm{SE}$ ) as a function of jaw length; September 1981. The regression is highly significant $\left(\mathrm{R}^{2}=82.2 \%, \mathrm{p}<0.001, \mathrm{n}=288\right.$ )

during which $<20 \%$ of the total biomass of prey taken by male curlews (bill length $\leq 12.5 \mathrm{~cm}$ ) consisted of prey other than Nereis diversicolor. After these 2 restrictions a total feeding time of $6335 \mathrm{~min}$ was left for analysis.

The search rate was estimated by measuring the pace frequency (time to make 50 steps during searching) and pace length (from prints in the mud). The search rate of curlews feeding within the grid of $5 \times 5 \mathrm{~m}$ plots could be estimated from the path length as predicted with the grid method (Reddingius et al. 1983). The path length equals the number of grid crossings multiplied by $\pi / 4$ times the side length of the plots (in our case $5 \mathrm{~m}$ ). On one day both methods of measuring search rate were used simultaneously and showed corresponding results (Table 1).

The estimation of worm size by most observers differed little: $39 \%$ of the worms taken by a curlew were estimated by 2 persons as having exactly the same length and $48 \%$ differed $1 \mathrm{~cm}$ only (Fig. 1). Size estimates were adjusted to take into account the small differences between observers. The field estimates were calibrated with the measurements in the laboratory by holding living worms near the bill of stuffed curlews during sessions comparable to the situation in the field (at the same distance and using the same telescopes). The field estimates are on average $0.5 \mathrm{~cm}$ below the measurements in the laboratory (Fig. 2).

Pellet analysis gave another check on the estimated prey sizes. Four times we collected a pellet which was regurgitated by individuals observed during an entire low water period in late summer 1981. The jaws of Nereis diversicolor give a good prediction of worm length (Fig. 3). There is a close agreement between 


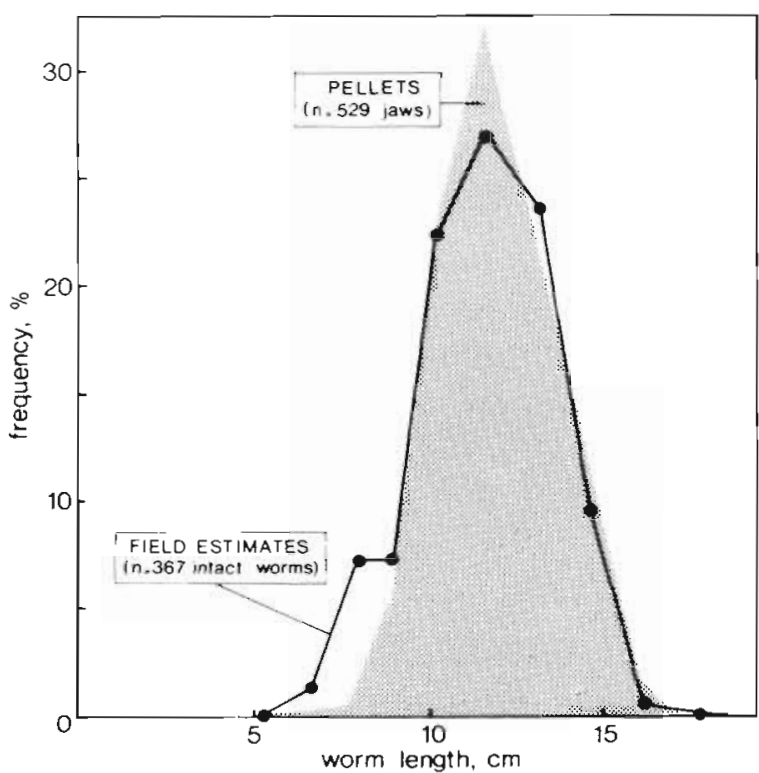

Fig. 4. Numenius arquata feeding on Nereis diversicolor. Check on field estimates of worm length by analysis of pellets (cf. Fig. 3). Four pellets were produced by individual curlews which had been observed during entire low water periods in September 1981

the frequency distribution of worm sizes as estimated in the field and as derived from the pellets (Fig. 4).

Prey. The methods used to determine length, weight, burrow depth and feeding activity of Nereis diversicolor are described in Esselink \& Zwarts (1989). A core sampler $(15 \mathrm{~cm}$ diameter, $40 \mathrm{~cm}$ deep) was used to determine worm density. The core was sieved through a $1 \mathrm{~mm}$ sieve in plenty of sea water. Although the smaller worms were not always retained on the $1 \mathrm{~mm}$ sieve, no worms $>6 \mathrm{~cm}$ were missed (Table 2), which means that the size classes selected by curlews were sampled accurately (cf. Table 2 and Fig. 9B).

Analysis. SPSS (Nie et al. 1975) was used for all statistical analyses.

\section{RESULTS}

\section{Prey handling}

Two types of prey capture were distinguished: (1) $N_{\text {peck, }}$ Nereis diversicolor taken in a rapid, single peck from the surface or the entrance of the burrow, (2) $N_{\text {probe, }} N$. diversicolor which a curlew obtains after probing, sometimes as deep as its eyes. $N_{\text {probe }}$ concerns a worm which tries to escape by remaining at the bottom of its burrow or by creeping towards the other corridor of the generally U-shaped burrows. Curlews were often seen to probe alternately in both entrances. Probing curlews could also sometimes suddenly 'freeze'

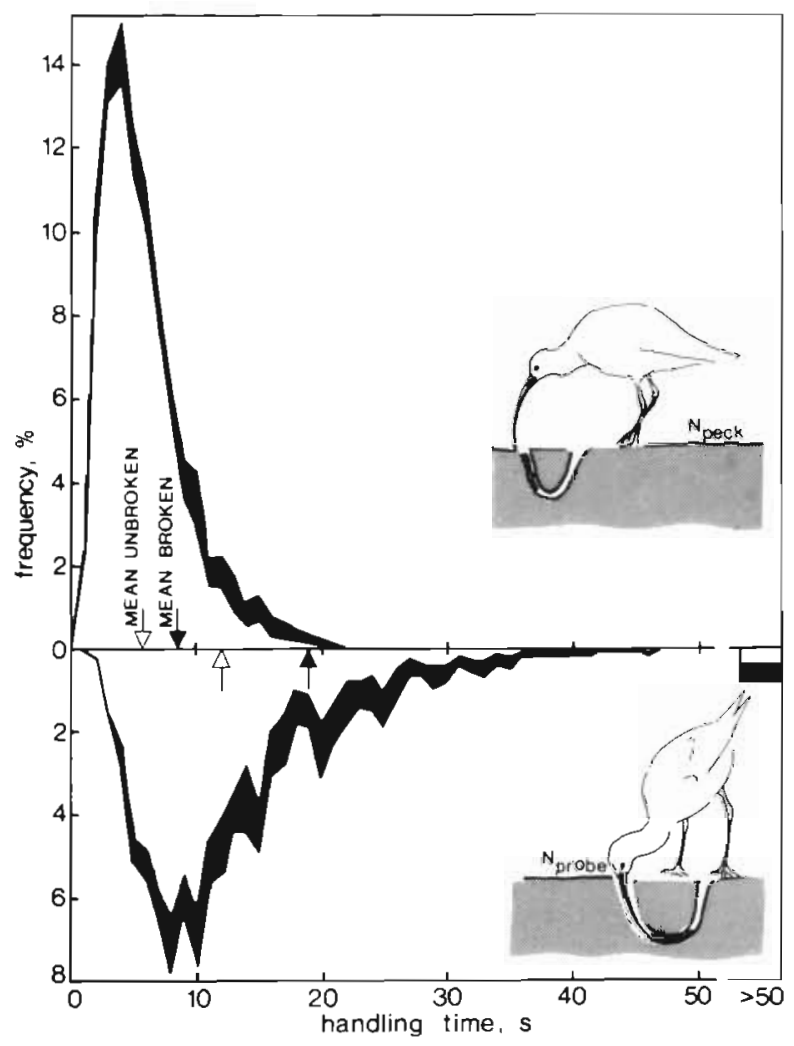

Fig. 5. Numenius arquata feeding on Nereis diversicolor. Frequency distribution of handling times for worms taken from the surface or entrance of burrow $\left(\mathrm{N}_{\text {peck }}\right)$ or deeply from burrow (N $N_{\text {probe }}$ ). Broken worms (black area) took significantly more time than intact worms (open area) $\left(\mathrm{N}_{\text {peck }}: \mathrm{R}^{2}=8.8 \%, \mathrm{p}<\right.$ $0.001, \mathrm{n}=6230 ; \mathrm{N}_{\text {probe }}: \mathrm{R}^{2}=9.8 \%, \mathrm{p}<0.001, \mathrm{n}=2519$ ). An $\mathrm{N}_{\text {probe }}$ takes more time than an $\mathrm{N}_{\text {peck }}\left(\mathrm{R}^{2}=28.9 \%, \mathrm{p}<0.001, \mathrm{n}\right.$ $=8749$ )

and remained motionless for 10 to $60 \mathrm{~s}$, apparently waiting for an upward movement of $N$. diversicolor.

$N_{\text {peck }}$ lasted 2 to $7 \mathrm{~s}$, usually $4 \mathrm{~s}$, while $N_{\text {probe }}$ took on average nearly 3 times as long (Fig. 5). The longest handling time of $N_{\text {probe }}$ ever observed was $128 \mathrm{~s}$. The handling of an $N_{\text {peck }}$ included catching and swallowing of the prey, but it took more time if the worm is washed in a nearby tidal pool. The major time-component of $N_{\text {probe }}$ was the probing preceding the eating. The handling time of a broken worm was an average of $2 \mathrm{~s}$ longer for $N_{\text {peck }}$ and $6 \mathrm{~s}$ for $\mathrm{N}_{\text {probe. }}$ Broken worms from which one fragment was eaten did not require more time than intact worms, but the handling time increased if the worm was extracted from the mud as 2 or more pieces. $\mathrm{N}_{\text {probe }}$ worms broke more often than $N_{\text {peck }}$ (Figs. 5 and 6A), probably because a worm present in its burrow can offer more resistance and/or is less easy to seize firmly than a worm on the surface.

Only $5 \%$ of the worms of the $N_{\text {peck }}$ type taken from a 'dry' surface broke as compared to ca $30 \%$ of those taken from an area covered by water (Fig. 6A). This is 
Table 2. Nereis diversicolor. Fraction of worms passing the $1 \mathrm{~mm}$ sieve, but retained on a $0.5 \mathrm{~mm}$ sieve; from Blomert (unpubl.). It is likely that small worms pass the $0.5 \mathrm{~mm}$ sieve, so that an even larger number of the smaller worms are missed when the $1 \mathrm{~mm}$ sieve is used

\begin{tabular}{|c|c|c|c|c|c|c|c|c|}
\hline Size $(\mathrm{cm})$ & 1 & 2 & 3 & 4 & 5 & 6 & 7 & $>7$ \\
\hline $\mathrm{n}$ & 2302 & 1217 & 378 & 98 & 60 & 57 & 44 & 325 \\
\hline Passing $(\%)$ & 84 & 75 & 59 & 31 & 22 & 4 & 2 & 0 \\
\hline
\end{tabular}

one reason we assume that an $\mathrm{N}_{\text {peck }}$ from a dry surface is captured when extended from the burrow, while prey taken from a water film also include filter-feeding worms present in the entrance of a burrow.

\section{Searching}

A curlew selecting $N_{\text {peck }}$ walked 3 times as fast as a bird taking $N_{\text {probe }}$ (Fig. 7). Prey of the $N_{\text {peck }}$ type are either on the surface or in the burrow entrance and thus easy to see. The high search rate is thus probably a way to increase the encounter rate with potential prey. A curlew selecting $\mathrm{N}_{\text {probe }}$ does not probe continuously in order to find worms within reach. On the contrary, it scans the surface carefully, apparently to detect tracks left by Nereis diversicolor. This is probably the reason the bird has to walk slowly. There is evidence, however, that a curlew searching for $\mathrm{N}_{\text {probe }}$ does not simply sample each burrow detected: 80 to $100 \%$ of all $\mathrm{N}_{\text {probe }}$ were taken from burrows covered by a water film.
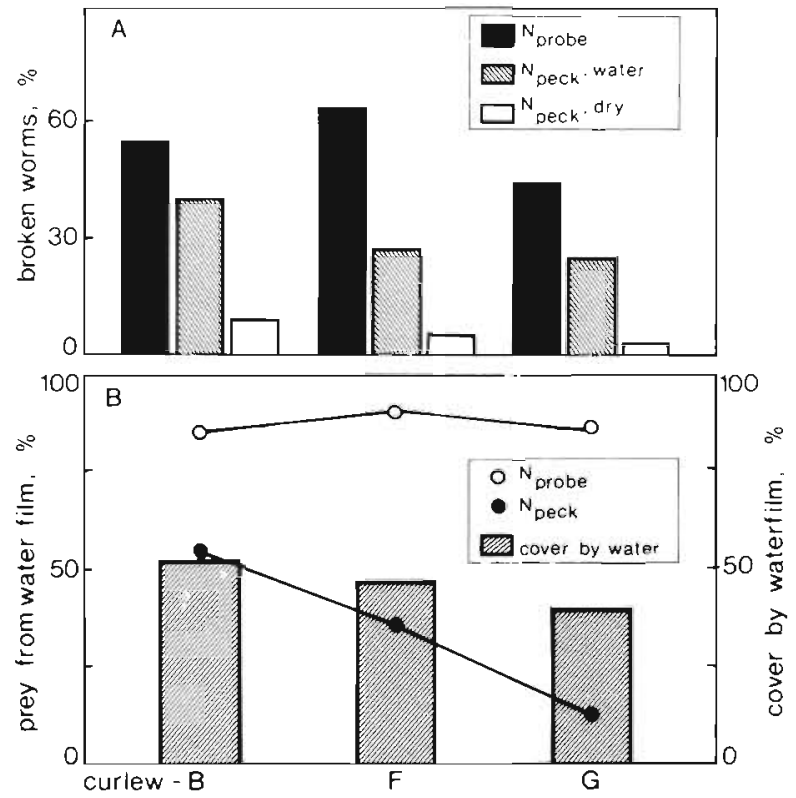

Fig. 6. Numenius arquata feeding on Nereis diversicolor. (A) Percent of broken worms taken by 3 curlews in late summer: Curlews B ( $n=521), F(n=1405)$ and $G(n=567)$. (B) Percent of $N_{\text {peck }}(\bullet)$ and $N_{\text {probe }}(0)$ taken from mud covered by water film for Curlews B, F and G; same data as in upper panel. Histograms show average coverage by water film in the 3 curlew territories
Since the average water cover amounted to only 40 to $50 \%$, curlews predominantly selected $N_{\text {probe }}$ from a substrate covered by water, whereas they took $N_{\text {peck }}$ relatively more often from a dry surface (Fig. 6B). We know from our own observations that Nereis burrows are easily visible on the dry surface and it therefore seems unlikely that better detectability of the burrow itself is the reason why curlews take more $N_{\text {probe }}$ from mud covered by water.

A curlew can select purely $\mathrm{N}_{\text {peck }}$ or $\mathrm{N}_{\text {probe }}$ for hours, but more often the 2 types of prey capture were mixed. $\mathrm{N}_{\text {probe }}$ rarely occurred by itself in long runs. If all days of observation are split into 30 min periods, solely $N_{\text {peck }}$ or $\mathrm{N}_{\text {probe }}$ are found in $28 \%$ and $5 \%$ of the periods, respectively; $67 \%$ is thus mixed. Sequence analysis within these mixed 30 min periods shows that curlews do not ignore one capture type during feeding, for the order in which both prey types occur appears to be random (Fig. 8).

\section{Size selection}

The size frequency distribution of Nereis diversicolor is bimodal for each late summer in the $3 \mathrm{yr}$ of observation (Fig. 9A). There is one large peak at 3 to $5 \mathrm{~cm}$ and another, lower and less pronounced, for the size class 9 to $12 \mathrm{~cm}$. The first peak represents juveniles which have become large enough to be retained on the $1 \mathrm{~mm}$ sieve. The density of the 0 -group in late summer is at least twice as large as indicated in Fig. 9A, due to smaller worms being missed (Table 2).

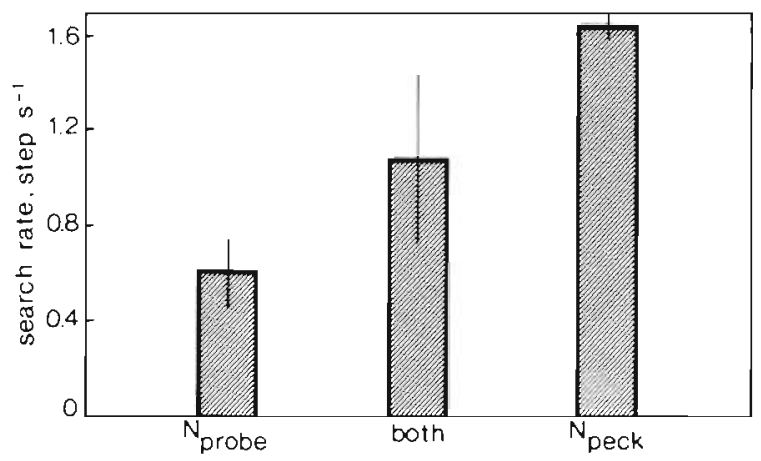

Fig. 7. Numenius arquata. Search rate (step $\mathrm{s}^{-1}$ ) if all prey within a 3 min period were $N_{\text {peck }}, N_{\text {probe }}$, or a mixture of both. Differences are significant $\left(\mathrm{R}^{2}=64.2 \%, \mathrm{p}<0.001, \mathrm{n}=66\right)$. All data are from male curlews in late summer 1981 


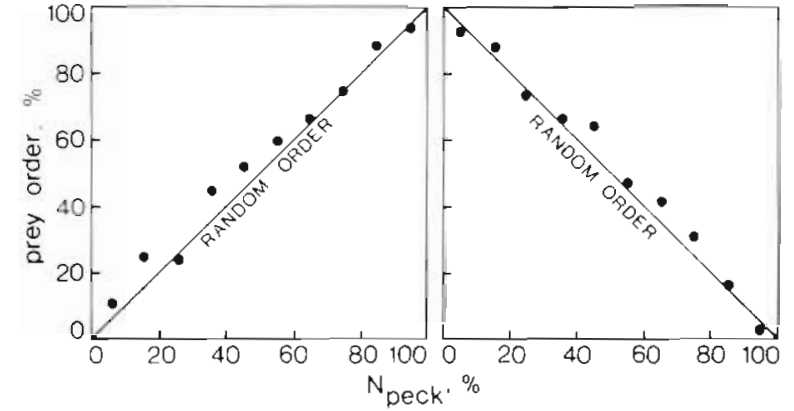

Fig. 8. Numenius arquata feeding on Nereis diversicolor. Probability that $2 \mathrm{~N}_{\text {peck }}$ (left panel) or $2 \mathrm{~N}_{\text {probe }}$ (right panel) will follow each other, as a function of percent of prey being $N_{\text {peck }}$ during a 30 min feeding period; each graph based upon 2409 prey. Diagonals show the expectation if the sequence is random

Whatever the density of juvenile worms, curlews ignored them completely (Fig. 9B). Most worms taken from the surface were 10 to $15 \mathrm{~cm}$ and the same size classes formed the majority of $\mathrm{N}_{\text {probe. The average size }}$ of $N_{\text {probe }}$ and $N_{\text {peck }}$ was exactly the same, $10.8 \mathrm{~cm}$. Worms present in the mud, as well as prey captured, were larger in 1979 than in both other years.

The relative size selection can be calculated by dividing per size class 'proportion taken' (Fig. 9B) by 'proportion present' (Fig. 9A, after a correction is made for small worms passing the $1 \mathrm{~mm}$ sieve; Table 2). The selection curves (Fig. 9C) are similar for the 3 yr. Predation risk was very low for Nereis diversicolor $\leq 6 \mathrm{~cm}$ and maximal for the larger worms.

The size frequency distributions of intact (Fig. 9B) and broken worms differ: most broken worms were 6 to $11 \mathrm{~cm}$ and appeared, on average, $2 \mathrm{~cm}$ shorter than non-broken ones. A broken worm taken as one piece is by definition a fragment, but if more pieces are taken it is often unclear whether the entire worm has been eaten. If prey were broken, the length of each piece was estimated separately and summed. There is no reason to believe that small worms break more frequently, so we assume that the mean size of broken and intact worms is in fact the same and that the $2 \mathrm{~cm}$ difference equals the uneaten fragment in broken worms.

The profitability of Nereis diversicolor depends on its size as well as whether the prey is taken as $N_{\text {peck }}$ or as $N_{\text {probe }}$. Ash-free dry weights of worms of 5 and $16 \mathrm{~cm}$ differ 13-fold (Fig, 10A). The handling time of $\mathrm{N}_{\text {peck }}$ merely doubles within that range and is virtually independent of size for $\mathrm{N}_{\text {probe }}$ (Fig. 10B). Hence the yield per handling time increases with size (Fig. 10C).

The flesh content of a broken worm can be estimated by converting length into weight in the same way as in the intact prey. This will, however, usually give a large underestimation: for instance, a broken worm of $6 \mathrm{~cm}$ being the half of a worm of $12 \mathrm{~cm}$ weighs 2.4 times as much as a worm of $6 \mathrm{~cm}$. Since we assume that broken and intact worms have on average the same length, we have calculated the weight of broken worms as the quotient of the prey length and mean prey length $(10.8 \mathrm{~cm})$ multiplied by the weight of a $10.8 \mathrm{~cm}$ worm. The adjusted profitability of $\mathrm{N}_{\text {peck }}$ and $\mathrm{N}_{\text {probe }}$ declines by $7 \%$ and $12 \%$, respectively, if the broken worms are included in the calculations (Table 3 ). The profitability is still lower if it is taken into account that a curlew probing without success cannot search for other prey in the meantime. This 'wasted time' has to be added to the successful handling times, by which the average profitability of $N_{\text {probe }}$ decreases again by $28 \%$ (Table 3 ).

\section{Seasonal variation}

Sightings of individually marked curlews showed that most of them remained in the study area from their arrival in July until their departure in April (Ens \& Zwarts 1980a). During this time their food supply changed drastically. The proportion of large Nereis diversicolor ( $\geq 13 \mathrm{~cm}$ ) with burrows within the reach of a male's bill decreased from $35 \%$ in July to $5 \%$ in November and $0 \%$ during the winter (Fig. 11A). The accessible fraction of smaller worms $(9$ to $12 \mathrm{~cm}$, there-

Table 3. Numenius arquata feeding on Nereis diversicolor. Handling time (mean \pm SD) and profitability (mean \pm SD) for $N$ peck and $N_{\text {prober }}$ calculated for intact worms, broken + intact worms and for $N_{\text {probe }}$ also broken + intact worms, unsuccessful probing time inclusive

\begin{tabular}{|c|c|c|c|}
\hline & $\begin{array}{l}\text { Handling time } \\
\qquad(s)\end{array}$ & $\begin{array}{c}\text { Profitability } \\
\text { (mg AFDW } \mathrm{s}^{-1} \text { ) }\end{array}$ & $\mathrm{n}$ \\
\hline \multicolumn{4}{|l|}{$N_{\text {peck }}$} \\
\hline Intact & $5.49 \pm 3.09$ & $20.46 \pm 15.04$ & 5341 \\
\hline All (broken + intact) & $5.91 \pm 3.50$ & $19.11 \pm 14.71$ & 6230 \\
\hline \multicolumn{4}{|l|}{ Nprobe } \\
\hline Intact & $12.31 \pm 7.77$ & $8.78 \pm 6.41$ & 1832 \\
\hline All (broken + intact) & $14.11 \pm 9.37$ & $7.73 \pm-5.99$ & 2519 \\
\hline All (probing inclusive) & 19.56 & 5.58 & 2519 \\
\hline
\end{tabular}




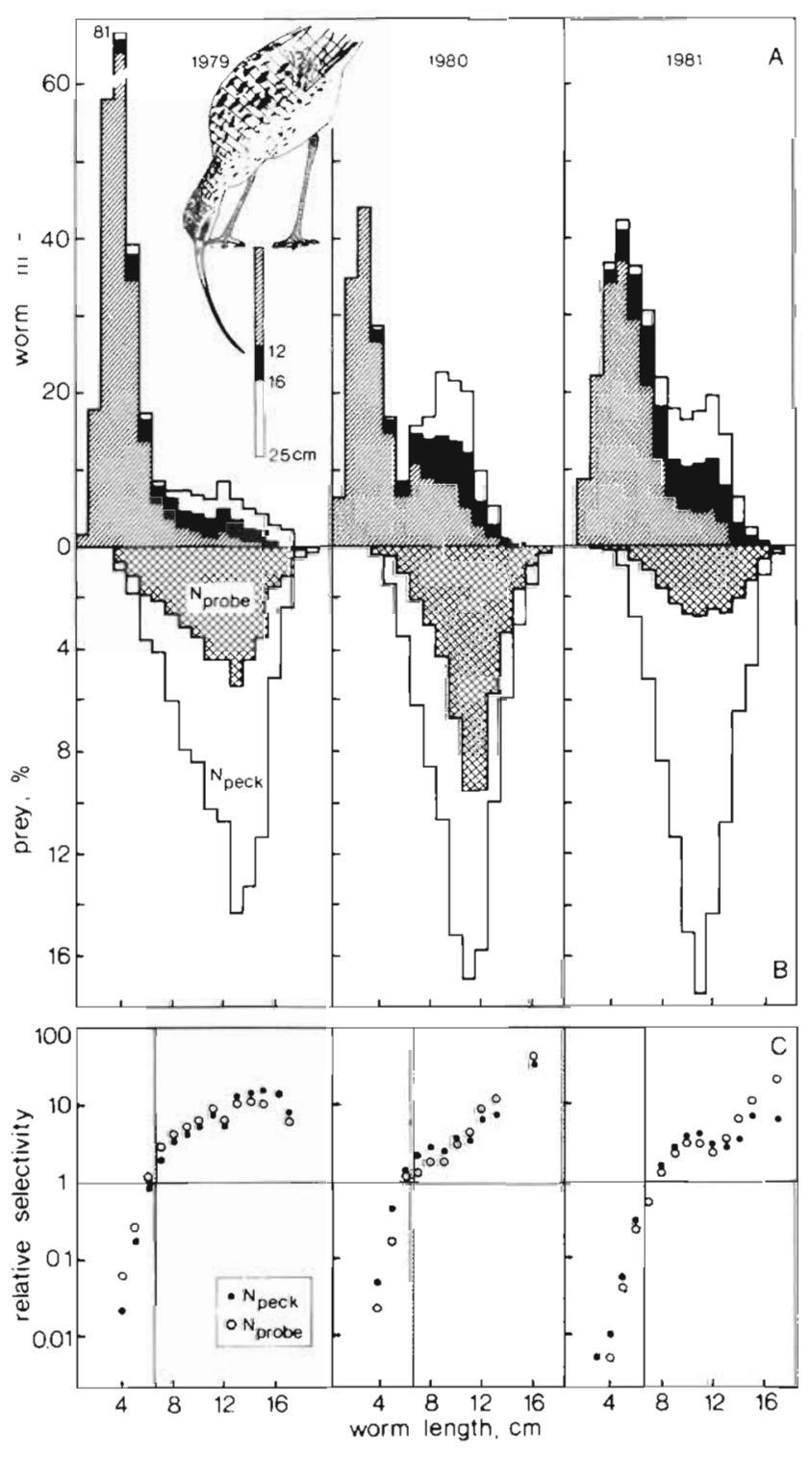

Fig. 9. Numenius arquata feeding on Nereis diversicolor (A) Density $\mathrm{m}^{-2}$ of worms per cm class in the study area during 3 late summers. Each frequency distribution is based upon ca 600 core samples of $1 / 56 \mathrm{~m}^{2}$. The known depth distribution per size class in sandy substrate during summer (see Fig. 2 in Esselink \& Zwarts 1989) has been used to calculate the density in the upper 12 and $16 \mathrm{~cm}$. (B) Size frequency distribution of intact worms taken by male curlews in July to September 1979 $(\mathrm{n}=1292), 1980(\mathrm{n}=1489)$ and $1981(\mathrm{n}=2658) ; \mathrm{N}_{\text {probe }}$ (crosshatched) and $\mathrm{N}_{\text {peck }}$ (open). Graphs based upon running means calculated for 3 classes. (C) Relative selectivity for $N_{\text {peck }}(\bullet)$ and $N_{\text {probe }}(0)$ given as ratio between prey taken and prey present in the substrate (see 2 upper panels); prey $\leq 6 \mathrm{~cm}$ (shaded area) are under-represented

fore just above the lower acceptance level) decreased in the same period from nearly $80 \%$ to $20 \%$

Searching in the $N_{\text {probe }}$ mode makes no sense if burrow depths exceed the bill length, and indeed $N_{\text {probe }}$ nearly disappeared during the course of the autumn
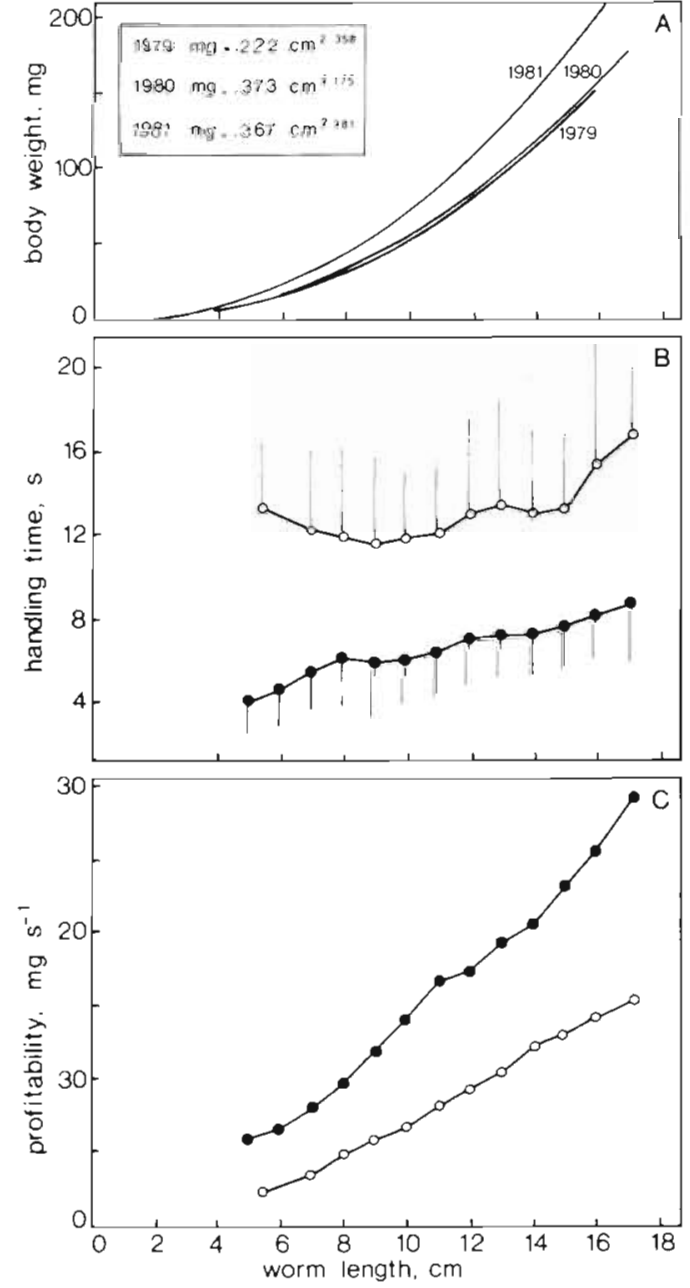

Fig. 10. Numenius arquata feeding on Nereis diversicolor. (A) Body weight (mg AFDW) of worms as a function of their length in September during 3 yr. The allometric relations are given $\left[R^{2}>99.9 \%, p<0.001, n=1682(1979), 1219(1980)\right.$ and 783 (1981)]. (B) Handling time (means \pm SD) of nonbroken prey taken by male curlews as a function of worm length for $N_{\text {peck }}(\bullet)$ and $N_{\text {probe }}(0)$; n varies between 6 and 907 ; total $\mathrm{n}=7173$ prey. (C) Profitability (mg AFDW s ${ }^{-1}$ handling $\pm S E)$ of intact prey as a function of worm length for $N_{\text {peck }}(\bullet)$ and $\mathrm{N}_{\text {probe }}(\mathrm{O})$. Same data as $(\mathrm{B})$

(Fig. 11B). A part of this loss was compensated by a higher intake of $\mathrm{N}_{\text {peck }}$, but the total intake of Nereis diversicolor decreased by ca $45 \%$ during the autumn (Fig. 11B).

It is to be expected that the average size of $N_{\text {probe }}$ shortened in the course of the autumn because the average size of worms remaining within reach of the bill decreased too (Fig. 11A). Indeed, the average size of $\mathrm{N}_{\text {probe }}$ decreased $1 \mathrm{~cm}$ from July to winter. No significant trend was found in $\mathrm{N}_{\text {peck }}$ : on average its size remained the same during the course of the year (Fig. 11C).

Substrate temperature had no effect on the feeding rate of curlews in summer or autumn, when the tem- 

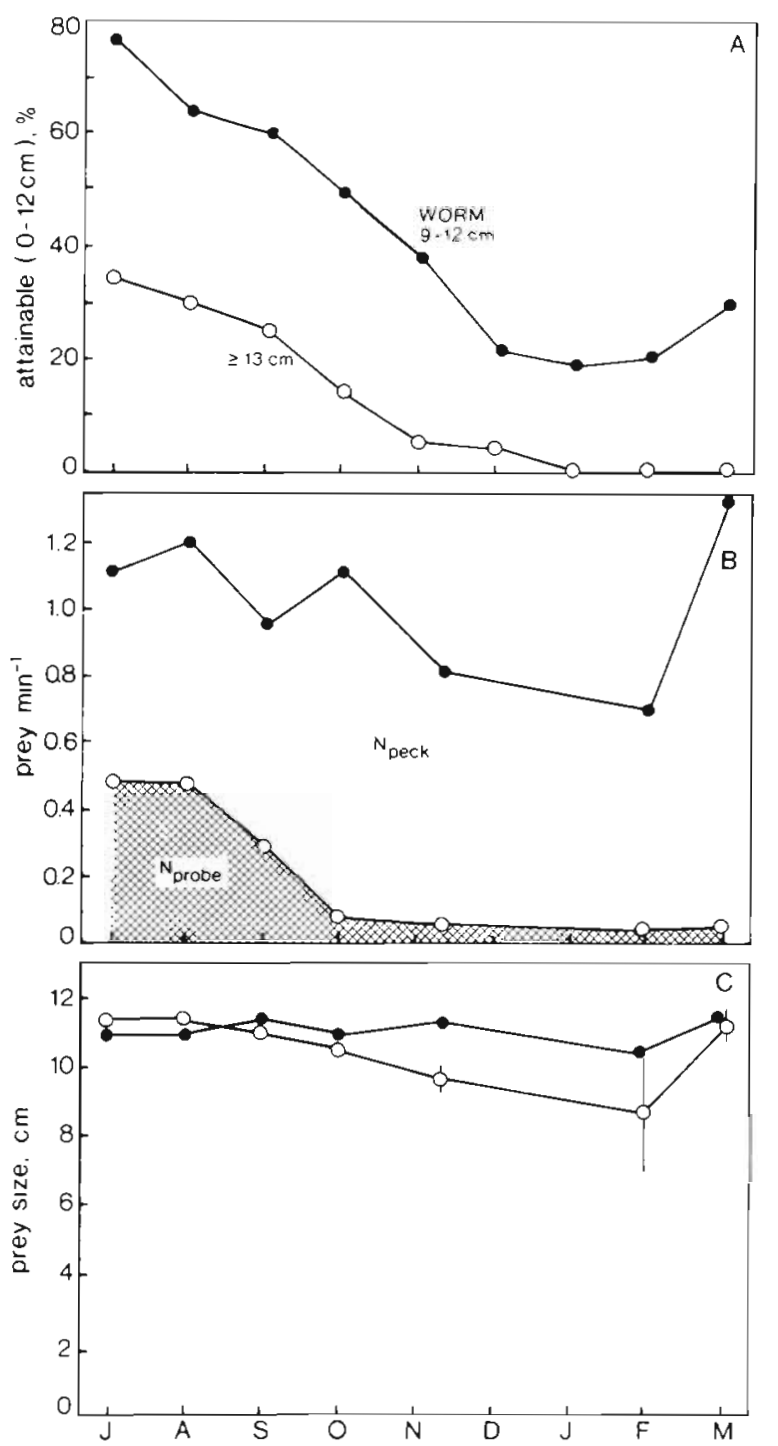

Fig. 11. Numenius arquata feeding on Nereis diversicolor. (A) Percentage of worms present in burrows in the upper $12 \mathrm{~cm}$ of the substrate for 2 size classes [ 9 to $12 \mathrm{~cm}(\bullet)$ and $\geq 13 \mathrm{~cm}(0)]$ from July to March (data from Esselink \& Zwarts 1989). (B) Prey min ${ }^{-1}$ feeding for $N_{\text {peck }}$ (open area) and $N_{\text {probe }}$ (crosshatched) during the course of the year. Means per month are calculated for each year separately and averaged after that. Each month is based upon several low water periods and at least $350 \mathrm{~min}$ of feeding, except February ( $2 \mathrm{~d}$ and $157 \mathrm{~min}$ ). The one day in December was lumped with November. Results of two 1-way analyses of variance (based upon a total feeding time of $6335 \mathrm{~min}$ ): $\mathrm{N}_{\text {peck }}: \mathrm{R}^{2}=2.8 \%, \mathrm{p}<0.001 ; \mathrm{N}_{\text {probe }}$ : $\mathrm{R}^{2}=24.3 \%, \mathrm{p}<0.001$. (C) Worm length (means $\pm \mathrm{SE}$ ) of

$\mathrm{N}_{\text {peck }}$ (-) and $\mathrm{N}_{\text {probe }}(0)$ during the course of the year

perature lay between 2 and $24{ }^{\circ} \mathrm{C}$. This seems to be different for February-March, because temperature has a highly significant effect on feeding rate, which increased from 0.6 to 1.8 prey $\mathrm{min}^{-1}$ with a rise in mud temperature from 1 to $8{ }^{\circ} \mathrm{C}$. However, this effect was
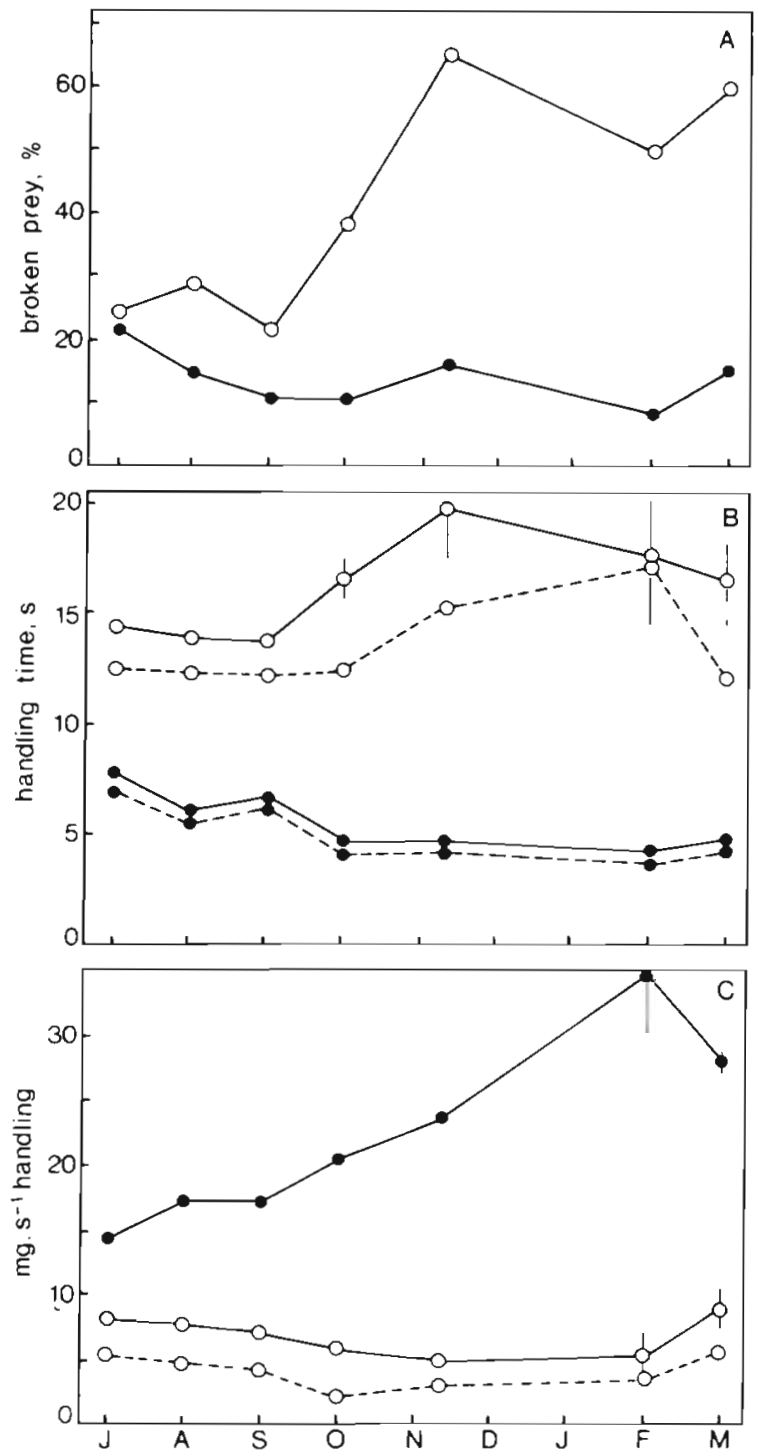

Fig. 12. Numenius arquata feeding on Nereis diversicolor. (A) Percentage broken $N_{\text {peck }}(\bullet)$ and $N_{\text {probe }}(0)$ during the course of the year. Total is 8749 worms, with at least 400 per month, except February $(n=136)$. (B) Handling time (means $\pm S E$ ) of $\mathrm{N}_{\text {probe }}\left(0: \mathrm{R}^{2}=0.8 \%, \mathrm{p}<0.01, \mathrm{n}=2519\right)$ and $\mathrm{N}_{\text {peck }}\left(\bullet: \mathrm{R}^{2}=\right.$ $7.2 \%, \mathrm{p}<0.001 ; \mathrm{n}=6230$ ) during the course of the year. Handling time of non-broken worms is indicated by dashed lines. (C) Profitability (mg s${ }^{-1}$ handling) of $\mathrm{N}_{\text {peck }}\left(\bullet: \mathrm{R}^{2}=9.2 \%\right.$, $\mathrm{p}<0.001, \mathrm{n}=6230)$ and $\mathrm{N}_{\text {probe }}\left(0: \mathrm{R}^{2}=1.0 \%, \mathrm{p}<0.001, \mathrm{n}=\right.$ 2519 ) during the course of the year; dashed line shows the profitability of $N_{\text {probe }}$ including unsuccessful probing time

not found within any single day, so it is unlikely that substrate temperature has a direct short-term effect on prey availability.

About $25 \%$ of $\mathrm{N}_{\text {probe }}$ broke during summer and more than $50 \%$ in winter (Fig. 12A). The most likely explanation is the greater burrow depth in winter, making it more difficult for a curlew to grasp the prey well. The increase in handling time in the same period from 15 to 
20 s can partly be attributed to the increased proportion of broken worms (Fig. 12B), but the effect is still present for intact worms, indicating that depth itself causes an increase in handling time.

In contrast to $\mathrm{N}_{\text {probe, }}$ the proportion of broken $\mathrm{N}_{\text {peck }}$ decreased from $25 \%$ in summer to $10 \%$ in winter (Fig. 12A). Also, the average handling time declined from $8 \mathrm{~s}$ in July to $5 \mathrm{~s}$ in October, remaining at the same level afterwards (Fig. 12B). This decline cannot be explained by a decrease in broken worms, since the trend was the same for unbroken worms. The decrease in handling time as well as in the proportion of broken $\mathrm{N}_{\text {peck }}$ indicates that Nereis diversicolor became easier to capture later in the season, which is the consequence of a seasonal shift in the feeding behaviour of $N$. diversicolor, as will be discussed later.

Although we could not observe whether $N_{\text {peck }}$ was taken from the entrance of the burrow or from the surface, we are convinced that all prey of the $\mathrm{N}_{\text {peck }}$ type in winter are taken from the surface whereas this is probably not always the case in summer. The handling time is reduced to seizing and swallowing if $N$. diversicolor is taken from the surface, but if the prey is extracted from the burrow it has more opportunity to retreat, resulting in a longer handling time and a higher proportion of broken worms. Two explanations for both effects are conceivable. Either the proportion

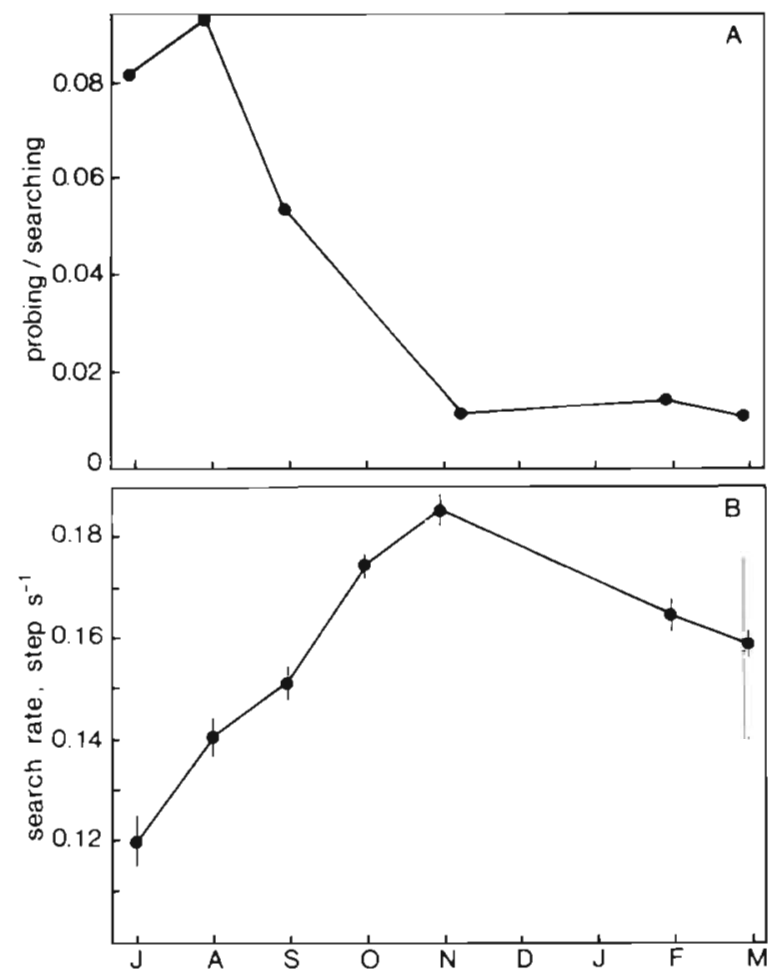

Fig. 13. Numenius arquata. (A) Probing time as ratio of searching time during the course of the year. Same data as in Fig. 11B. (B) Search rate (step $\mathrm{s}^{-1} \pm \mathrm{SE}$ ) during the course of the year $\left(R^{2}=17.4 \%, p<0.001, n=585\right)$ of worms taken from the surface increases during the season or substrate temperature might influence the rapidity with which a worm can retreat into its burrow. According to our analyses, however, temperature has no direct effect on handling time nor on the proportion of broken worms, so we favour the first explanation.

The profitability of $\mathrm{N}_{\text {probe }}$ decreased during the course of the season (Fig, 12C) because handling time increased (Fig. 12B), more prey broke (Fig. 12A) and prey size decreased. If probing time is taken into account as 'negative handling time' the prey value is still lower (Fig. 12C). Meanwhile, profitability of $N_{\text {peck }}$ increased because all effects work the other way around: less prey broke, handling time decreased and prey size remained constant.

The disappearance of $\mathrm{N}_{\text {probe }}$ during the autumn correlates with a change in the searching behaviour: there was less probing (Fig. 13A) and an increase in the search rate (Fig. 13B). However, if unsuccessful probing is considered in relation to the total handling time of $\mathrm{N}_{\text {probe, }}$ there was a relative increase: in July $38 \mathrm{~s}$ was spent probing for each $100 \mathrm{~s}$ handling $\mathrm{N}_{\text {probe }}$ and this ratio rose gradually to $62 \mathrm{~s}$ per $100 \mathrm{~s}$ handling in October.

\section{Tidal trends}

Individual curlews were observed during 40 entire low water periods of 4 to $7 \mathrm{~h}$. There were large differences from day to day, but in general the intake of $\mathrm{N}_{\text {probe }}$ was maximal during ebbing tide and sometimes again during the flood, whereas $N_{\text {peck }}$ was usually taken at low water. The daily variation, shown for 2 days in Fig. 14B, can partly be explained by the water film which remains at the surface (Fig. 14A). Cover by water film decreases gradually after exposure, but wind-force and wind-direction cause a large variation in the decrease in coverage by water film during receding tide.

The feeding rate of $N_{\text {peck }}$ generally reached a peak 3 to $4 \mathrm{~h}$ after emersion. The rate at which a curlew took $\mathrm{N}_{\text {peck }}$ coincided with the frequency at which Nereis diversicolor occurred at the surface during the course of the exposure period (see Fig. 9 in Esselink \& Zwarts 1989).

$\mathrm{N}_{\text {probe }}$ dominated during ebbing tide. The rate at which the water film disappeared seemed to determine the feeding rate of $\mathrm{N}_{\text {probe, }}$ but on many days $\mathrm{N}_{\text {probe }}$ was limited to the first $2 \mathrm{~h}$ of the low water period, even at sites where the water cover remained high for a longer time (Fig. 15). The occurrence of $\mathrm{N}_{\text {probe }}$ corresponded with our observations on filter feeding by Nereis diversicolor, which is also limited to surfaces covered by a water film during the first $2 \mathrm{~h}$ after exposure (Figs. 10 and 11 in Esselink \& Zwarts 1989). 

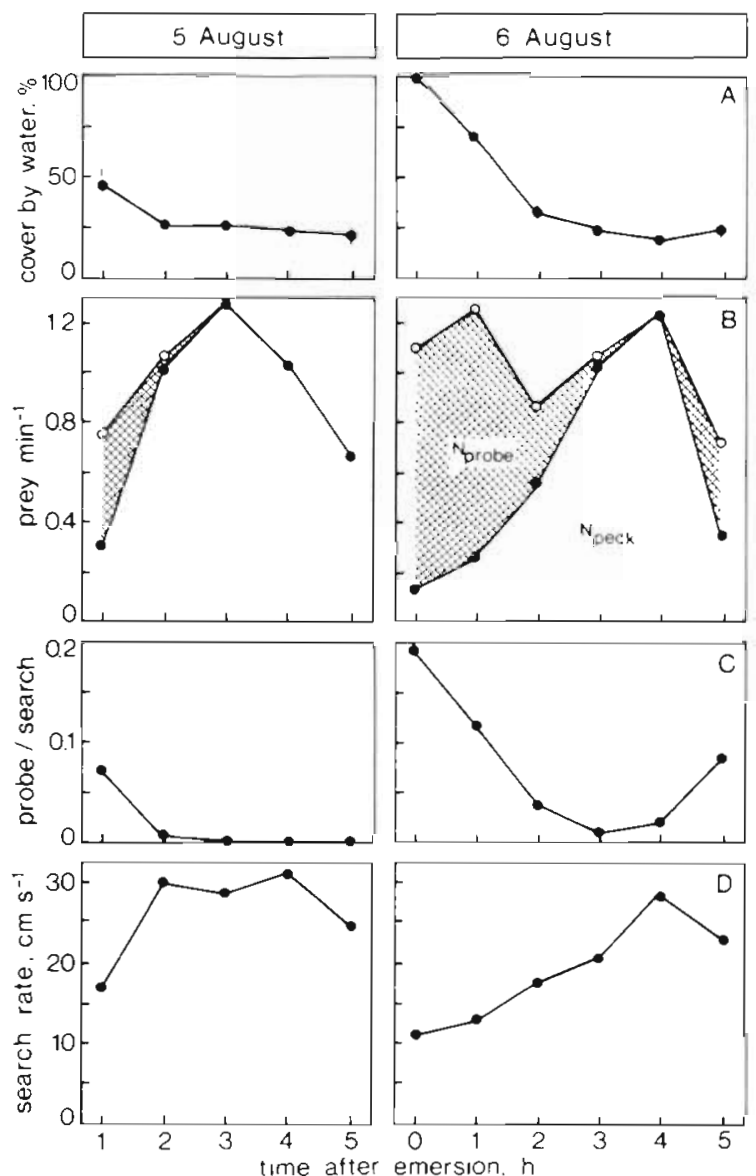

Fig. 14. Numenius arquata. Water film and feeding behaviour of Curlew F on 5 and 6 August 1981 during the course of the low water period. (A) Coverage by water film (mean $\pm \mathrm{SE}$ ) in $5 \times 5 \mathrm{~m}$ plots visited. (B) Prey min $^{-1}$ feeding for $N_{\text {peck }}$ (open area) and $\mathrm{N}_{\text {probe }}$ (cross-hatched). (C) Probing time as ratio of searching time. (D) Search rate $\left(\mathrm{cm} \mathrm{s}^{-1}\right)$ as derived from the number of grid crossings (cf. Table 1)

\section{Behaviour of curlew after experimentally raised prey accessibility}

We were able to elicit surface activity of Nereis diversicolor in the laboratory by spreading out minced meat over the mud surface (Fig. 10B in Esselink \&

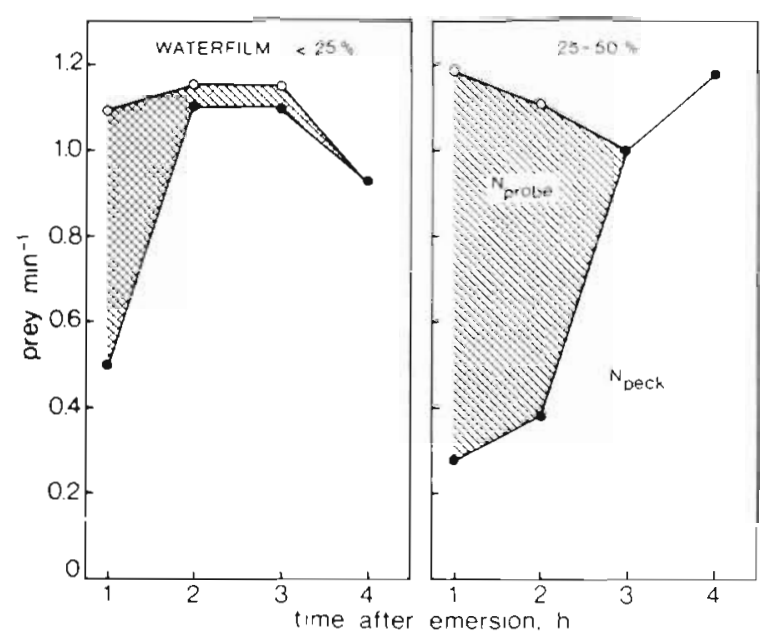

Fig. 15. Numenius arquata. Prey $\mathrm{min}^{-1}$ feeding for $\mathrm{N}_{\text {peck }}$ (open area) and $N_{\text {probe }}$ (cross-hatched) during the course of the low water period in $5 \times 5 \mathrm{~m}$ plots where coverage by water film during a visit of Curlew $\mathrm{F}$ was $<25 \%$ (left panel) or 25 to $50 \%$ (right panel). Same data as Fig. 14; both days combined. Twoway analyses of variance show that time after exposure and to a lesser degree water film itself have significant effects on the intake rate; also the interaction is significant $\left(\mathrm{N}_{\text {peck }}\right.$ : total $\mathrm{R}^{2}=$ $39.6 \%, \mathrm{p}<0.001, \mathrm{n}=458 \mathrm{~min} ; \mathrm{N}_{\text {probe: }}$ total $\mathrm{R}^{2}=17.8 \%$, $\mathrm{p}<0.001, \mathrm{n}=458 \mathrm{~min})$

Zwarts 1989). The same experiment was repeated in the field. A $50 \mathrm{~m}$ hose was used to bring $30 \mathrm{l}$ of a slurry of minced meat from the observation tower to the feeding territory of Curlew F just after the exposure of the mudflat. It was not possible to quantify the surface activity of the worms, but if the effect were the same as in the laboratory, it was to be expected that the curlew would take more worms from the surface and less from the burrows. The slurry which spread out over an area of ca $5 \mathrm{~m} \times 20 \mathrm{~m}$ had a clear effect on the feeding behaviour of the curlew, which spent a remarkable amount of its feeding time near the end of the hose. Comparison with a control situation was possible, since the bird was also observed during 3 preceding low water periods (Table 4 ). The feeding rate on the experimental day was $19 \%$ above the average in the control situation, which was achieved by a $25 \%$ increase of

Table 4. Numenius arquata. Feeding behaviour of Curlew $F$ in its feeding territory during a day when a slurry of meat was spread out over the mud in order to increase surface feeding of Nereis diversicolor (experiment on 12 September $1981 ; 168$ worms captured) compared to 3 preceding low water perods (control'; 393 worms captured; SE calculated over the means of the 3 observation periods)

\begin{tabular}{lccc|}
\hline & Control & Experiment & Difference \\
\hline Feeding rate $\left(\right.$ Nereis $\left.\mathrm{min}^{-1}\right)$ & $0.86 \pm 0.05$ & 1.02 & $+19 \%$ \\
Feeding rate $\left(\mathrm{N}_{\text {peck }} \mathrm{min}^{-1}\right)$ & $0.79 \pm 0.07$ & 0.99 & $+25 \%$ \\
Feeding rate $\left(\mathrm{N}_{\text {probe }} \mathrm{min}^{-1}\right)$ & $0.07 \pm 0.03$ & 0.03 & $-57 \%$ \\
Broken worms $(\%)$ & $16.6 \pm 7.1$ & 2.2 & $-87 \%$ \\
Search rate $\left(\mathrm{cm} \mathrm{s}^{-1}\right)$ & $18.4 \pm 0.8$ & 17.7 & $-4 \%$ \\
\hline
\end{tabular}


$\mathrm{N}_{\text {peck. }}$. Hardly any worm broke during the experiment, which also suggests that Curlew F was able to seize $N$ diversicolor easily from the surface.

\section{DISCUSSION}

\section{Prey availability}

The distinction between $N_{\text {peck }}$ (prey detected at the surface) and $\mathrm{N}_{\text {probe }}$ (prey taken from its burrow after a track reveals its presence in the mud) is not an absolute one. On the one hand, a curlew might detect a surfacefeeding worm but be too late to catch it and subsequently try to catch the prey in its burrow. If that were to occur often, no large deviation would be found in the frequency with which both prey types are taken from dry and wet surfaces. As this difference, however, is very large (Fig, $6 \mathrm{~B}$ ), it is unlikely that prey of the $\mathrm{N}_{\text {probe }}$ type are often detected as surface-feeding worms. On the other hand, worms present close to the entrance might be taken just in a single peck and be classified as $\mathrm{N}_{\text {peck. }}$. It is reasonable to assume that this kind of prey breaks more often than worms taken at the surface. Indeed ca $5 \%$ of $\mathrm{N}_{\text {peck }}$ from a dry surface broke as compared to ca $30 \%$ if this prey type is taken from a substrate covered by water (Fig. 6A), indicating that the latter category also includes at least some filterfeeding worms. We assume that this problem of interpretation is more likely in summer (when filtering is common) than in winter (when filter feeding is rare), since the handling time of $N_{\text {peck }}$ and the proportion of broken $\mathrm{N}_{\text {peck }}$ decreased from late summer to winter (Fig. 12). In other words, all worms of the $\mathrm{N}_{\text {probe }}$ type are presumably captured when filter feeding, while $N_{\text {peck }}$ are surface-feeding and sometimes filter-feeding worms.

In this section we will estimate the density of available prey, if a curlew selects solely worms of the $\mathrm{N}_{\text {peck }}$ or $\mathrm{N}_{\text {probe }}$ variety. Nereis diversicolor occur with a total density of at least 200 to $400 \mathrm{~m}^{-2}$ in the study area during late summer (Fig. 9A; Table 2), but the density relevant for curlews is reduced to ca $100 \mathrm{~m}^{-2}$ on average, since prey $<7 \mathrm{~cm}$ are ignored.

The density of worms available as $N_{\text {peck }}$ depends mainly on the surface activity of Nereis diversicolor. Surface activity was measured during 5 field days in September-October (Esselink \& Zwarts 1989). Not a single worm was recorded during 3 low water periods, while during the other 2 low water periods, surface activity took up only 0.1 to $0.2 \%$ of the time. This means that a curlew can expect not more than 1 worm at the surface per 5 or $10 \mathrm{~m}^{2}$ at any one time. Moreover, the density of surface-feeding worms actually accessible to feeding curlews is even lower since $N$. diver- sicolor retreat quickly into their burrows if they detect any visible stimulus or vibration in the substrate (Linke 1939, Vader 1964, own obs.).

Because of this anti-predator reaction, the frequency at which worms appear at the surface is probably a more relevant measure of prey availability than total time spent at the surface. The minimal $N_{\text {peck }}$ feeding rate directly after emersion and the maximal intake ca 3 h later, observed for an individual curlew (Fig. 14B), agree with the frequency of Nereis diversicolor surface bouts observed during the low water period (Fig. 9 in Esselink \& Zwarts 1989), In late summer, $N$. diversicolor emerged not more than 1 to 4 times per $300 \mathrm{~min}$ from their burrows (Esselink \& Zwarts 1989). If the prey density is $100 \mathrm{~m}^{-2}$, the search rate is $25 \mathrm{~cm} \mathrm{~s}^{-1}$, and assuming a field of view of 1 (or 2?) $\mathrm{m}$, one might expect that a curlew has to walk 10 to $50 \mathrm{~m}$ (or 5 to $25 \mathrm{~m}$ ?) before a worm is found. We know that a curlew in late summer has to cover a distance of 12.5 to $25 \mathrm{~cm}$ per $N_{\text {peck }}$ taken, given the measured search rate $(25 \mathrm{~m}$ $\mathrm{s}^{-1}$ ) and search time (50 to $100 \mathrm{~s}$ ) per prey. It is thus likely that all prey encountered are captured, certainly if it is taken into account that some worms retreat quickly into their burrow if a curlew approaches.

The highest feeding rate was measured in the second half of March, when the search time per $N_{\text {peck }}$ was half as long as in late summer (Fig. 11B). We suppose that the surface activity of Nereis diversicolor in spring is high (as found by Twisk 1986) because of the bloom of benthic algae caused at that period by a combination of irradiation and temperature (Colijn \& de Jonge 1984), whereas at the same time the concentration of food in the overlying water is still too low to make filter feeding worthwhile. A high feeding rate during sunny periods in spring was also observed in oystercatchers feeding on $N$. diversicolor (Ens pers. comm.) and brent geese Branta bernicla (Drent \& van Eerden pers. comm.). We conclude that the tidal as well as the seasonal variation in feeding rate of $\mathrm{N}_{\text {peck }}$ can largely be explained by the frequency at which the worms appear at the surface.

The accessibility of worms caught as $\mathrm{N}_{\text {probe }}$ depends on the burrow depth. In late summer $60 \%$ of Nereis diversicolor $\geq 7 \mathrm{~cm}$ had burrows beyond the reach of male curlews, reducing the density of accessible prey to 40 worms $\mathrm{m}^{-2}$. Such a density is apparently too low to probe at random, so a curlew searches on the surface for detectable prey. In late summer $60 \%$ of all probes were unsuccessful, which is equivalent to the proportion of burrows too deep for male curlews. $N$. diversicolor cannot be detected if there is no visible entrance to the burrow. An entrance formed by an active worm may disappear again (Evans 1987) and therefore inactive worms usually have no holes at the surface. Worms filter feeding are, upon close observation, detectable: their burrows are always visible, and there is either a 
water current or other traces of activity within the burrow entrance (Twisk 1986, Esselink \& Zwarts 1989). Filter feeding cannot occur on dry surfaces and is generally restricted to the first $2 \mathrm{~h}$ of the exposure time (Twisk 1986, Esselink \& Zwarts 1989). N Nrobe indeed tended to be taken from substrate covered by water film (Fig. 6), especially towards the beginning of the emersion time (Figs. 14 and 15). The $\mathrm{N}_{\text {probe }}$ type disappeared for 2 reasons during the course of the autumn. First, the worms spend less time filter feeding, so that fewer worms are detectable. Second, fewer worms remain accessible because of the increase in burrow depth (Fig. 11A).

\section{Detection and recognition of profitable prey}

Curlews feeding on Nereis diversicolor usually select the larger worms. Worms of $12 \mathrm{~cm}$ occurred, for example, 5 times more often in the diet than worms of $6 \mathrm{~cm}$ (Fig. 9B). The selection of larger worms is more pronounced if one takes into account the density of all prey sizes (Fig. 9A). Worms of $12 \mathrm{~cm}$ were then taken 8 times more often than worms of $6 \mathrm{~cm}$ (Fig. 9C).

The selection curves in Fig. 9C are similar for the 3 yr and there is also no difference between selectivity for $N_{\text {probe }}$ and $N_{\text {peck. }}$. The selectivity is calculated by dividing the frequency of prey sizes taken by the frequency of prey sizes present in the substrate. This does not say much, however, about the active selection for size when the accessible fraction is not the same for all size classes. Such information is lacking for $N_{\text {peck, but }}$ because the depth distribution for each size class is known this can be used to calculate the selection of accessible prey of the $\mathrm{N}_{\text {probe }}$ type. Worms which belong to the prey sizes which are ignored have burrows within reach of the bill, but the larger the worms the greater the fraction with burrows deeper than the bill length (Fig. 16A). The selection of larger $N_{\text {probe }}$ becomes thus more pronounced, taking into account the accessibility of the worms (Fig. 16B): worms of $12 \mathrm{~cm}$ are now selected 23 times more often than the size class $6 \mathrm{~cm}$.

Optimal foraging theory can assist us in explaining why small worms are not taken. A predator maximizing its intake rate has to ignore all prey for which the energy gain during handling is below the general intake rate during feeding and has to take each profitable prey encountered, i.e. prey for which $\mathrm{mg} \mathrm{s}^{-1}$ handling is above $\mathrm{mg} \mathrm{s}^{-1}$ feeding (Hughes 1980, Krebs et al. 1983).

The profitability of $N_{\text {peck }}$ and $N_{\text {probe }}$ increases with size because although curlews handle small worms relatively rapidly, this is not fast enough given the small amount of flesh taken (Fig. 10). The prey value
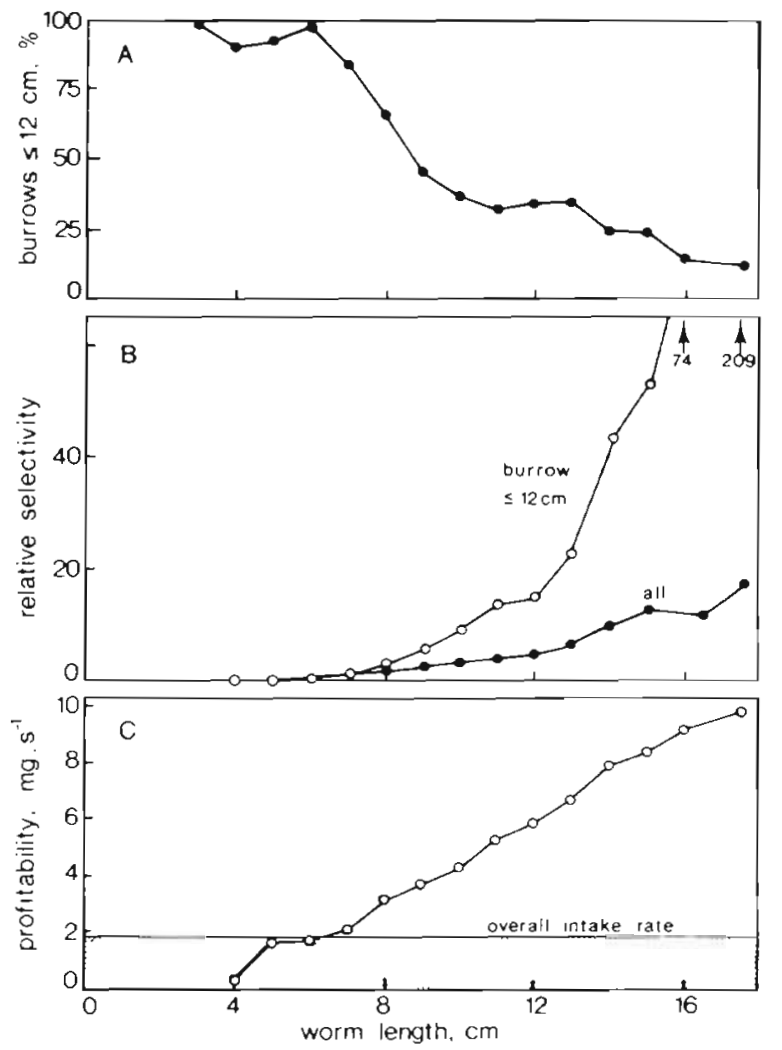

Fig. 16. Numenius arquata feeding on Nereis diversicolor. (A) Accessibility of $\mathrm{N}_{\text {probe }}$ worms (percent of burrows found in the upper $12 \mathrm{~cm}$ of the substrate; clay content $\leq 5 \%$ ) as a function of worm length during late summer (same data as Fig. 2 in Esselink \& Zwarts 1989). (B) Relative size selection on $N_{\text {probe }}$ as a function of worm length in late summer, averaged for the 3 yr (same data as Fig. 9C). Lower graph shows the selectivity without taking into account the increase of burrow depths with size. Upper graph takes into account the relative number of worms found in the upper $12 \mathrm{~cm}$ of the substrate (Fig. 16A) (C) Profitability ( $\mathrm{mg} \mathrm{s}^{-1}$ handling) of $N_{\text {probe }}$ including broken worms and probing time (cf. Table 3) as a function of worm length. Feeding rate ( $\mathrm{mg} \mathrm{s}^{-1}$ feeding) is indicated

curves, shown in Fig. $10 \mathrm{C}$, concern intact prey only. The profitability decreases $9 \%$ for $N_{\text {peck }}$ and $12 \%$ for $N_{\text {probe }}$ if broken prey are included and again $28 \%$ for $\mathrm{N}_{\text {probe }}$ if all unsuccessful probing times are reckoned as handling times (Table 3). The adjusted profitabilities of $\mathrm{N}_{\text {probe }}$ (Fig. 16C) are thus $36 \%$ below the prey values for intact worms and successful probes only (cf. Fig. 10C).

The intake rate of male curlews in late summer and autumn was, according to our data, $1.9 \mathrm{mg} \mathrm{s}^{-1}$ feeding on average. The profitability of all size classes of $N_{\text {peck }}$ is above this lower limit: the yield of an $N_{\text {peck }}$ of $5 \mathrm{~cm}$ is $5 \mathrm{mg} \mathrm{s}^{-1}$, and making an extrapolation downward worms of $4 \mathrm{~cm}$ should still be profitable, but in fact they are not taken.

For all size classes $\mathrm{N}_{\text {probe }}$ is less profitable than $\mathrm{N}_{\text {peck }}$. The rare $N_{\text {probe }} \leq 6 \mathrm{~cm}$ is below the predicted lower 
limit and $2.2 \mathrm{mg} \mathrm{s}^{-1}$ for an $\mathrm{N}_{\text {probe }}$ of $7 \mathrm{~cm}$ is just above the intake rate of $1.9 \mathrm{mg} \mathrm{s}^{-1}$ (Fig. 16C). According to the simple optimal diet equation there should be a step change in the selectivity at a worm of $\mathrm{ca} 7 \mathrm{~cm}$. As in many other empirical studies (Krebs et al. 1983), this is not the case - rather there is a gradual increase of selectivity with size.

One of the assumptions of the classical optimal diet model is that predators know the energy value of all encountered prey, whereas it is more realistic to suppose that predators can only estimate prey values and thus must take mistakes (Rechten et al. 1983). A curlew which detects a worm at the surface must derive its size from the prey width, since usually only a part of the body emerges from the burrow. $\mathrm{N}_{\text {probe }}$ is extracted from the substrate. Its size can be estimated only from the width of the entrance of the burrow. Although we have not quantified the relationship between width of the corridor and worm length, we are convinced that there is a close relationship, also because body width and body length are well correlated (Esselink \& Zwarts 1989). The width of the corridor offers a good prediction of the size of the bivalve Mya arenaria (Zwarts \& Wanink 1989), but if the width of the corridor is measured at the surface instead of halfway, the accuracy decreases considerably, as some of the tubes are funnel-shaped and others straight (Zwarts unpubl.). If the same applies for Nereis diversicolor, it will not be easy for a curlew to deduce worm length and thus prey value from the size of holes at the surface of the substrate.

We conclude that curlews select larger worms because they are the most profitable. Deviations from the expected step change in size selection might be explained by the misidentification of prey size. An alternative explanation is that small prey are simply less detectable.

\section{Optimal search rate}

An increase in search rate raises the encounter rate with prey but the number of prey overlooked may increase so much that the net profit will be lower. The trade-off between search rate and probability of detection depends on the conspicuousness of the prey. This idea has been worked out in a model (Gendron \& Staddon 1983) which has been tested with prey with a different crypticity (Gendron 1986).

A curlew searching for Nereis diversicolor has to deal with 2 types of prey which both demand a specific search rate. Capturing prey from the burrows can be considered as the situation of maximal crypsis. The curlew walks slowly at 6 to $10 \mathrm{~cm} \mathrm{~s}^{-1}$ (Figs. 7, 13B and $14 \mathrm{D}$; Table 1). Its posture is hunched forward with the bill just above the surface. On the other hand, the search rate increase by a factor of 3 if all prey are of the $N_{\text {peck }}$ mode. Still larger is the difference in area searched per unit time, since the search path, although this has not been quantified, must also be much wider. A curlew searching for $\mathrm{N}_{\text {peck }}$ walks upright and appears to detect worms at a distance of 1 to $2 \mathrm{~m}$.

Though searching for $N_{\text {peck }}$ and $N_{\text {probe }}$ requires a different search technique, there is no evidence that curlews ignore one type of prey and concentrate on the other. Both prey types occur together, and if only one prey type is taken, this can be explained by the behaviour of the prey. If the prey types are mixed, the order in which they are taken is completely random (Fig. 8), which also suggests that feeding curlews do not ignore one of the 2 prey types.

Curlews taking a mixture of $N_{\text {probe }}$ and $N_{\text {peck }}$ have an intermediate search rate (Fig. 7). A shift from one prey type to the other is accompanied by a change in the search rate within a tidal cycle (Fig. 14) as well as over the year (Figs. 11B and 13B). The data from these figures have been summarized in Fig. 17. One can conclude from this that curlews continuously adjust their search rate to the ratio of $N_{\text {probe }}$ and $N_{\text {peck }}$ currently experienced. If a curlew for instance expects a few Nereis diversicolor at the surface, and detects many visible burrows, it will decrease its search rate. If a worm then appears at the surface within the restricted field of view of the bird, it will of course be taken, for $\mathrm{N}_{\text {peck }}$ is always a profitable prey. On the other

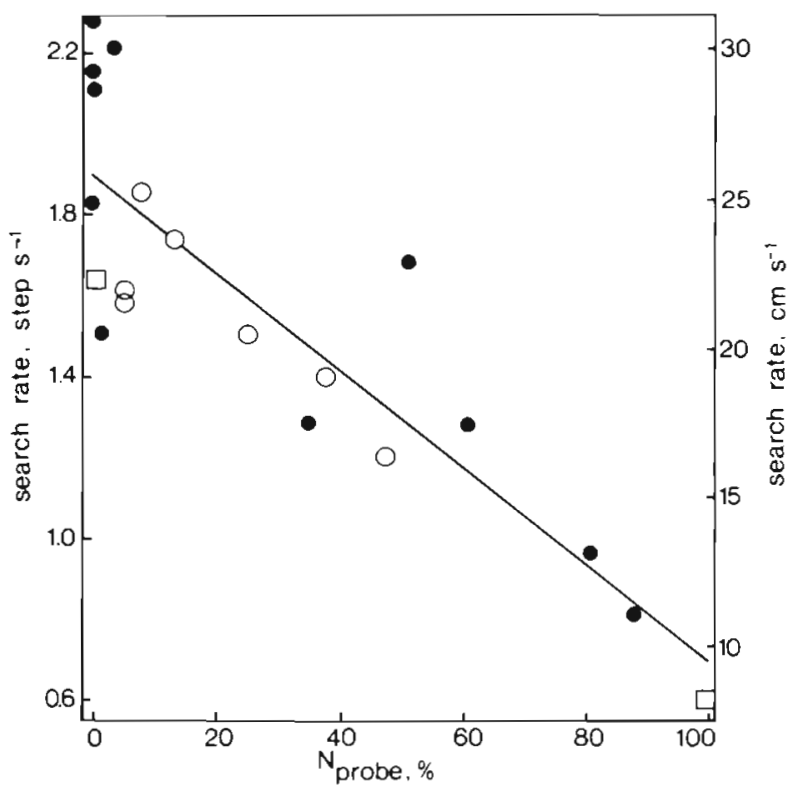

Fig. 17. Numenius arquata feeding on Nereis diversicolor. Search rate as a function of the relative occurrence of $N_{\text {probe }}$ (percent of worms being $\mathrm{N}_{\text {probe }}$ ) $\left\{\mathrm{R}^{2}=76.2 \%, \mathrm{p}<0.01, \mathrm{n}=\right.$

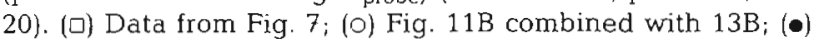
Fig. 14B combined with 14D 
hand, if many worms are at the surface and a curlew has quickened his pace to increase the encounter rate with $\mathrm{N}_{\text {peck, }}$ many potential $\mathrm{N}_{\text {probe }}$ will not be detected, but if the bird catches sight of a potential $N_{\text {probe, }}$ there is no reason to ignore it since it remains a profitable prey.

The general conclusion is that a feeding curlew which maximizes its intake rate while searching for Nereis diversicolor has to decide continuously how to anticipate changes in the behaviour of its prey.

Acknowledgements. Many students participated in this research. We would like to mention Jenny Cremer, Bruno Ens, Roelof Hupkes, Tjarda de Koe, Rick Looijen, Bertrin Roukema and Renske de Vries. We also thank Rudi Drent for supervision. Bruno Ens for his valuable discussions, and both him and John Goss-Custard for their comments on the manuscript. We are also grateful to Piet Zegers for catching the curlews, Wieberen Planting for preparing all figures, Jos Zwarts for making the bird vignettes, Leon Steijvers for writing a useful computer programme and Anne-Marie Blomert for access to her unpublished data.

\section{LITERATURE CITED}

Beukema, J. J. (1976). Biomass and species richness of the macrobenthic animals living on tidal flats of the Dutch Wadden Sea. Neth. J. Sea Res. 10: 236-261

Chambers, M. R., Milne, H. (1985). Life cycle and production of Nereis diversicolor O. F. Müller in the Ythan estuary. Estuar coast. mar. Sci. 3: 133-144

Colijn, F, de Jonge, V N. (1984). Primary production of microphytobenthos in the Ems-Dollard Estuary. Mar. Ecol. Prog. Ser. 14: 185-196

Curtis, D. J., Galbraith, C. G., Smyth, J. C., Thompson, D. B. A. (1985). Seasonal variations in prey selection by estuarine black-headed gulls (Larus ridibundus). Estuar. coast. Shelf Sci. $21 \quad 75-89$

Dales, R. P. (1950). The reproduction and larval development of Nereis diversicolor O. F. Müller. J. mar biol. Ass. U.K. 24: $321-360$

Dankers, N., Beukema, J. J. (1981). Distributional patterns of macrozoobenthic species in relation to some environmental factors. In: Dankers, N., Kühl, H., Wolff, W. J. (eds.) Invertebrates of the Wadden Sea. Balkema, Rotterdam, p. 69-103

Ens, B. J., Zwarts, L. (1980a). Wulpen op het wad van Moddergat. Watervogels 5: 108-120

Ens, B. J., Zwarts, L. (1980b). Territoriaal gedrag bij wulpen buiten het broedgebied. Watervogels 5: 155-169

Esselink, P., Zwarts, L. (1989). Seasonal trend in burrow depth and tidal variation in surface feeding of Nereis diversicolor. Mar. Ecol. Prog. Ser. 56: 243-254

Essink, K. (1978). The effects of pollution by organic waste on macrofauna in the eastern Dutch Wadden Sea. Neth. Inst. Sea Res., Publ. Ser. No. 1. 1-135

Evans, A. (1987). Relative availability of the prey of wading birds by day and by night. Mar Ecol. Prog. Ser 37 103-107

Evans, P. R., Herdson, D. M., Knights, P. J., Pienkowski, M. W (1.979). Short-term effects of reclamation of part of Seal sands, Teesmouth, on wintering waders and shelduck. I. Shorebird diets, invertebrate density and the impact of predation on the invertebrates. Oecologia (Berl.) 41 $183-206$
Gendron, R. P. (1986). Searching for cryptic prey: evidence for optimal search rates and the formation of search images in quail. Anim. Behav. 34: 898-912

Gendron, R. P., Staddon, J. E. R. (1983). Searching for cryptic prey: the effect of search rate. Am. Nat. 121: 172-186

Goerke, H. (1966). Nahrungsfiltration von Nereis diversicolor O. F. Müller (Nereidae, Polychaeta). Veröff. Inst. Meeresforsch. Bremerh. 10: 49-58

Goss-Custard, J. D. (1977). The energetics of prey selection by redshank (Tringa totanus) in relation to prey density. J. Anim. Ecol. 46: 1-20

Goss-Custard, J. D., Jones, R. E., Newberry, P. E. (1977). The ecology of the Wash. I. Distribution and diet of wading birds (Charadrii). J. appl. Ecol. 14: 681-700

Harley, M. B. (1953). The feeding habits of Nereis diversicolor. Br. J. Anim. Behav. 1: 88

Höfmann, H., Hoerschelmann, H. (1969). Nahrungsuntersuchungen bei Limikolen durch Mageninhaltsanalysen. Corax 3: 7-22

Hughes, R. N. (1980). Optimal foraging theory in the marine context Oceanogr. mar. Biol. A. Rev. 18: 423-481

Kersten, M., Piersma, T. (1984). Voedselkeuze en voedselopname van Zilverplevieren Pluvialis squatarola in de Waddenzee tijdens de voor-en najaarstrek. Limosa 57: 105-111

Krebs, J. R., Stephens, D. W., Sutherland, W. J. (1983). Perspectives in optimal foraging. In. Clark, G. A. (ed.) Perspectives in ornithology. Cambridge University Press, New York, p. 165-221

Linke, O. (1939). Die Biota des Jadebusenwattes. Helgoländer wiss. Meeresunters. 1 201-348

Muus, B. J. (1967). The fauna of Danish estuaries and lagoons. Distribution and ecology of dominating species in the shallow reaches of the mesohaline zone. Meddr Danm. Fisk.-og Havunders 5: 1-316

Nie, N. H., Hull, C. H., Jenkins, J. G., Steinbrenner, K., Bent, D. H. (1975). SPSS. McGraw-Hill, New York

Rechten, C., Avery, M., Stevens, A. (1983). Optimal prey selection: why do great tits show partial preferences? Anim. Behav. 31: 576-584

Reddingius, H., Schilstra, A. J., Thomas, G. (1983). The grid method in estimating the path length of a moving animal. J. Anim. Ecol. 52: 199-208

Smidt, E. L. B. (1951). Animal production in the Danish Waddensea. Meddr Kommn Danm. Fisk.-og Havunders. (Ser. Fisk) 11, 6: 1-151

Townshend, D. J. (1981). The importance of field feeding to the survival of wintering male and female curlews Numenius arquata on the Tees estuary. In: Jones, N. V., Wolff, W. J. (eds.) Feeding and survival strategies of estuarine organisms. Plenum Press, New York, p. 261-273

Twisk, F. (1986). Resultaten onderzoek beschikbaarheid bodemdieren voor vogels. Notitie 86.157 (internal paper), Rijkswaterstaat Tidal Waters Division, Middelburg

Vader, W. J. M. (1964). A preliminary investigation into the reactions of the infauna of the tidal fluctuations in water level. Neth. J. Sea Res. 2: 189-222

Wanink, J., Zwarts, L. (1985). Does an optimally foraging oystercatcher obey the functional response? Oecologia (Berl.) 67:98-106

Wolff. W J. (1973). The estuary as a habitat. An analysis of data on the soft-bottom macrofauna of the estuarine area of the rivers Rhine, Meuse and Scheldt. Zool. Verh., Leiden 126: $1-242$

Worrall, D H. (1984). Diet of the Dunlin Calidris alpina in the Severn estuary. Bird Study 31: 203-212

Zwarts, L. (1974). Vogels van het brakke getijgebied. Bondsuitgeverij, Amsterdam 
Zwarts, L. (1988). De bodemfauna van de Fries-Groningse Waddenkust. Flevobericht, Rijksdienst voor de IJsselmeerpolders, Lelystad

This article was presented by Professor J. J. Zijlstra, Den Burg, The Netherlands
Zwarts, L., Wanink, J. (1989). Siphon size and burying depth in deposit- and suspension-feeding bivalves. Mar Biol. 100: $227-240$

Manuscript first received: December 8, 1988 Revised version accepted: May 24, 1989 